\title{
Length of hospitalization is associated with selected biomarkers (albumin and lymphocytes) and with co-morbidities: study on 4000 patients
}

\author{
Antonio E. Pontiroli ${ }^{1}$, Lara Loreggian ${ }^{2}$, Marco P. L. Rovati ${ }^{2}$, Elena De Patto ${ }^{2}$, Laura Folini ${ }^{1}$, Federico Raveglia ${ }^{3}$, \\ Matilde De Simone ${ }^{4}$, Alessandro Baisi ${ }^{3}$ and Ugo Cioffi ${ }^{*}$
}

\begin{abstract}
Background: Low albumin levels and low lymphocyte counts are intra hospital conditions that exert a negative influence on prognosis, healing and length of hospitalization. The study aimed to analyze the correlation between low blood levels of albumin, low lymphocytes, and length of stay. The secondary aim was to identify other co-morbidities associated with prolonged hospital stay.

Methods: Retrospective pilot study was conducted by analyzing anamnestic and biochemical data, related to 4038 patients admitted to ten wards of Hospital San Paolo (Milan), collected from July $1^{\text {st }} 2012$ to December $31^{\text {st }} 2012$. A statistical analysis was carried out using the Correlation method, Multivariate Analysis and Regression. Lymphocyte count and co-morbidities were evaluated in the whole cohort, albumin levels in 1437 patients.

Results: In the whole sample, low albumin levels and low lymphocyte counts were directly correlated to longer hospitalizations. The stratification of the results by department and diagnosis suggests that there is a higher correlation in certain subpopulations, and albumin shows a greater correlation with length of stay than lymphocytes. Also advanced age, high platelets, type of diagnosis, male gender and emergency admission led to longer hospitalizations.

Conclusions: A routine check of albumin, lymphocytes and a spectrum of significant variables can provide precious information which can eventually lead to a shorter hospital stay. Knowledge of the general health status of a patient and the possibility to estimate his/her length of hospital stay are essential information for Clinical Governance, and for the improvement of internal services of hospitals on a large scale.
\end{abstract}

Keywords: Albumin, Lymphocytes, Length of stay, Co-morbidities, Screening method

\section{Bullet points}

1. Low levels of albumin and lymphocytes are highly correlated with prolonged hospitalizations.

2. Platelets, advanced age, number of co-morbidities, diagnosis, gender, urgent admission are also associated with prolonged hospitalizations

3. This routine screening will improve the hospitals internal healthcare along with helping to better
* Correspondence: ugo.cioffi@guest.unimi.it

${ }^{4}$ Department of Surgery, University of Milan, Milan, Italy

\footnotetext{
Full list of author information is available at the end of the article
}

allocate hospital resources in terms of budget and personnel; even for a clinical audit.

\section{Introduction \\ Background}

According to recent studies low albumin levels and low lymphocyte counts are the frequent in hospitalized patients, representing negative conditions with a negative impact on prognosis and length of stay (LOS) $[1,2]$. Actually, albumin and lymphocyte count are biochemical parameters successfully used in common clinical practices for highlighting and monitoring certain specific diseases [3]. Because of their importance in human 
biology and the variety of biochemical processes in which they take part, these markers are indices of general organic damage, unfavourable prognosis and malfunction; even if their role in determining nutritional status and length of stay is still debated [2, 4-14]. The ultimate goal of this study is to raise awareness among physicians about the health status of hospitalized patients, based on lymphocyte count and albumin levels at admission.

\section{Objectives}

The main objective is to verify the correlation between serum albumin levels, lymphocyte counts and length of stay in a vast hospital population, together with various blood parameters and patient history. We would like to create an innovative, economical and standardized screening method, based on albumin, lymphocyte count and an analysis of co-morbidities, in order to assess the organic status of patients and predict the length of recovery at admission. These informations would give the opportunity to improve the organization of hospitals internal services, giving patients better treatments and shortening hospitalizations and reducing social costs associated with long waiting times and incorrect diagnosis $[15,16]$.

\section{Methods}

\section{Study design, setting and participants}

This is a retrospective cohort study, which took place in Hospital San Paolo of Milan after the study protocol was approved by the local Ethics Committee. The study included all the patients in the following wards: Surgery $\left(1^{\text {st }}\right.$ and $2^{\text {nd }}$ ward), Gynecology, Obstetrics, Infectious Diseases, Medicine $\left(1^{\text {st }}, 2^{\text {nd }}\right.$, and $3^{\text {rd }}$ ward), Orthopedics, and Urology. The observation period was July $1^{\text {st }} 2012$ December $31^{\text {st }}$ 2012. Day Hospital patients were excluded from the study (since the study tested how low levels of albumin and lymphocytes influenced the length of stay). Data collection, through electronic charts, included recording of anamnestic data such as gender, age, date of admission and discharge, type of diagnosis, concomitant diseases (identified by the specific International Classification Code of Diseases) and biochemical indices like complete blood count with lymphocytes count and albumin measured during the first 24-48 h. Starting from electronic charts, we created an Excel database containing all informations registered for all patients, divided according to the ward of admission. Raw data was critically examined using the method of descriptive statistical analysis, and the results were stratified by type of admission (elective or urgent), by ward, and diagnosis.

In this study the ranges of albumin and lymphocytes considered normal were 3.5-5.0 g/dL and 1.0-3.0 $\times 10^{3} / \mathrm{ml}$ respectively, as described in Figs. 1 and 2. Consequently, levels of albumin and lymphocytes under $3.5 \mathrm{~g} / \mathrm{dl}$ and $1.0 \times 10^{3} / \mathrm{ml}$ were considered low.

\section{Statistical analysis}

The SAS 9.3 software and its related modules (SAS MACRO and SAS GRAPHS) were used for data cleansing, statistical models, descriptive statistics and graphs. JMP 11 was also used to enhance the models and the graphs. Using the Correlation method we studied the relationship between albumin, lymphocytes, and length of stay, verifying its extensibility in the various wards, then divided the patients by diagnosis and lastly studying the entire hospital population. To obtain a good statistical

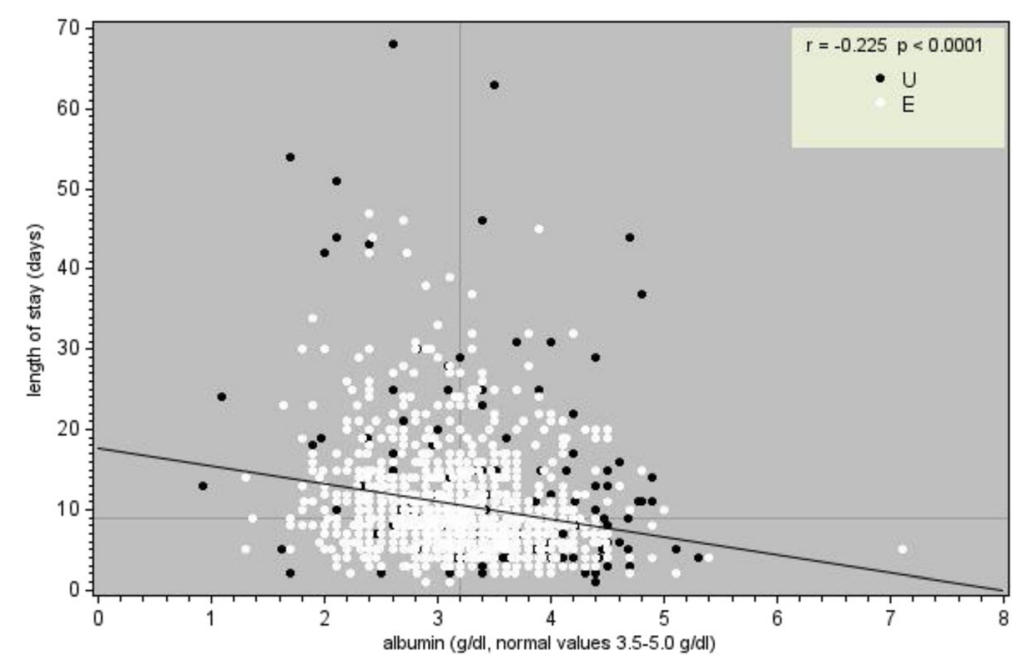

Fig. 1 Relationship between length of stay (days) and serum albumin levels ( $g / d l)$. Legend. White circles indicate patients with emergency admission; black circles indicate patients with routine admission 


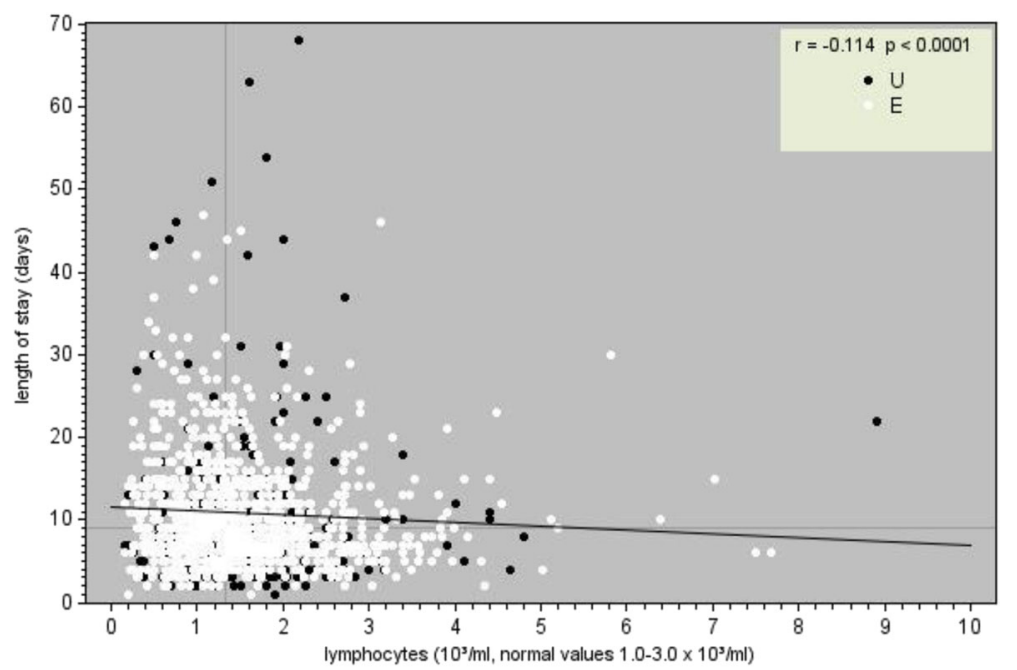

Fig. 2 Relationship between length of stay (days) and lymphocite count $\left(10^{3} / \mathrm{ml}\right)$. 1.0-3.0). Legend. White circles indicate patients with emergency admission; black circles indicate patients with routine admission

analysis we include the most popular wards. The sample was then divided into eight main "classes of diagnosis", based on the main types of diseases observed in our hospital population: Malignant tumors, Benign tumors, Inflammatory diseases, Infections, Bleeding conditions, Fractures, Pregnancy/Childbirth and Other. Even in this case statistical analysis was performed in order to examine type and intensity of the relationship between the hospital stay and low albumin and lymphocytes levels. At a later stage we used Regression analysis to highlight which other factors could influence length of stay, using Generalized Linear Models method (GLM). Finally, we studied the behavior of the variable "days of hospitalization" as a function of the number of comorbidities. Correlation was evaluated using Pearson's parametric coefficient while bivariate distribution was graphically represented using scatter plots.

For a more detailed and complete analysis we evaluate if there is a difference between two particular subgroups of the test sample: patients in which the albumin was measured and patients who do not present the value. The methodologies used to study the two groups were the Discriminant function analysis and the Multivariate stepwise method.

\section{Results}

\section{Analysis on the entire sample}

During the period of study 4038 people matched the inclusion criteria, thus distributed in hospital wards: Surgery $1^{\text {st }}(n=411)$, Surgery $2^{\text {nd }}(n=343)$, Gynecology $(n=149)$, Obstetrics $(n=1184)$, Infectious Diseases $(n$ $=206)$, Medicine $1^{\text {st }}(n=550)$, Medicine $2^{\text {nd }}(n=345)$, Medicine $3^{\text {rd }}(n=291)$, Orthopedics $(n=278)$, Urology $(n=281)$. Table 1 shows that some wards had a high rate of cases of albumin evaluation, here described in descending order: Medicine $1^{\text {st }}$, Infectious Diseases, Medicine $3^{\text {rd }}$, Medicine $2^{\text {nd }}$, and Surgery $2^{\text {nd }}$. Instead Orthopedics and Surgery $1^{\text {st }}$, followed by Urology, Gynecology and Obstetrics, had a very low rate of cases with evaluation of albumin. The measurement of albumin in the early hours of admission occurred only in $36 \%$ ( 1437 on 4038 , i.e. 1 out of 3 ) of the total cases, but lymphocyte count appeared to be a routine test, being measured in the totality of the cases $(n=4038)$. As shown in Table 2 the group consists of 1477 men and 2561 women, with age ranging from 8 to 105 years. Within this hospital population, the average age was 60.27 years (SD 22.90) and the median age was 60.81 years $\left(1^{\text {st }}\right.$ interquartile $=38.64 ; 3^{\text {rd }}$ interquartile $\left.=81.65\right)$. Table 3 shows the proportion of patients whose albumin and

Table 1 Evaluation of lymphocytes and albumin performed within 24-48 h of admission

\begin{tabular}{llll}
\hline Ward & Patients & Albumin evaluated & $\%$ Evaluation \\
\hline Surgery $1^{\text {st }}$ & 411 & 101 & $25 \%$ \\
${\text { Surgery } 2^{\text {nd }}}_{\text {Gynecology }}^{343}$ & 149 & 7 & $47 \%$ \\
Obstetrics & 1184 & 35 & $5 \%$ \\
Infectious Diseases $^{\text {st }}$ & 206 & 150 & $3 \%$ \\
Medicine $1^{\text {st }}$ & 550 & 432 & $73 \%$ \\
Medicine 2 & 345 & 237 & $79 \%$ \\
Medicine $3^{\text {rd }}$ & 291 & 206 & $69 \%$ \\
Orthopedics & 278 & 71 & $71 \%$ \\
Urology & 281 & 38 & $26 \%$ \\
Total & 4038 & 1437 & $14 \%$ \\
\hline
\end{tabular}

Lymphocytes were evaluated in all patients (100\%) 
Table 2 Main patient's characteristics

\begin{tabular}{|c|c|c|c|c|c|c|c|}
\hline Ward & Total patients & Nr. Male & Nr. Female & Minimum Age & Maximum Age & Mean Age & Median Age \\
\hline Surgery $1^{\text {st }}$ & 411 & 235 & 176 & 18 & 102 & $63.95 \pm 19.67$ & 66.90 \\
\hline Surgery $2^{\text {nd }}$ & 343 & 198 & 145 & 8 & 102 & $66.58 \pm 17.80$ & 71.59 \\
\hline Gynecology & 149 & 0 & 149 & 19 & 93 & $49.72 \pm 16.58$ & 45.72 \\
\hline Obstetrics & 1184 & 0 & 1184 & 15 & 94 & $36.17 \pm 6.93$ & 36.35 \\
\hline Infectious diseases & 206 & 130 & 76 & 20 & 90 & $55.57 \pm 17.04$ & 54.25 \\
\hline Medicine $1^{\text {st }}$ & 550 & 262 & 288 & 22 & 105 & $80.29 \pm 14.61$ & 84.24 \\
\hline Medicine 2nd & 345 & 178 & 167 & 22 & 104 & $79.59 \pm 14.92$ & 83.10 \\
\hline Medicine 3rd & 291 & 139 & 152 & 21 & 105 & $79.57 \pm 15.91$ & 83.83 \\
\hline Orthopedics & 278 & 125 & 153 & 8 & 102 & $68.01 \pm 21.88$ & 73.03 \\
\hline Urology & 281 & 210 & 71 & 22 & 96 & $67.74 \pm 16.13$ & 70.98 \\
\hline Total & 4038 & 1477 & 2561 & 8 & 105 & $60.27 \pm 22.90$ & 60.81 \\
\hline
\end{tabular}

lymphocytes levels were within the normal range at admission. There was a significant relationship between low albumin levels, low lymphocyte counts and length of stay in the whole sample (Figs. 1 and 2). From a statistical point of view, decreased albumin and decreased lymphocytes significantly correlate with an increase in hospital stay. We also observed the existence of a significant correlation between days of hospitalization and the number of co-morbidities $(r=0.4207 ; p<0.0001)$ taking into account other ten variables (Age, Red Blood Cell, Hemoglobin, Hematocrit, Mean Cell Volume, Mean Corpuscular Hemoglobin, Mean Corpuscular Hemoglobin Concentration, Platelets, White Blood Cell and Neutrophils) see (Table 4).

\section{Stratification of results by hospital ward}

The correlation between low levels of albumin and LOS applies to the wards of surgery, infectious diseases, medicine, orthopedics and urology (Table 5); in contrast, the rare measurement of albumin in gynecology and obstetrics unit does not allow to achieve statistical significance. Only in surgery and orthopedics wards, low lymphocyte counts significantly correlated with longer LOS. In all the other wards the relationship between lymphocytes and length of stay is not significant.

\section{Stratification of results by diagnosis}

The correlation between albumin and LOS applied to most of the classes of diagnosis identified (Table 6): malignant tumor, infections, bleeding conditions, fractures, pregnancy/childbirth and miscellaneous conditions (Others). Low levels of albumin were not related to increased length of stay only in benign tumors and inflammatory diseases. In the presence of diagnosis of malignant tumor and pregnancy/childbirth, even though there was a correlation between low levels of albumin and length of stay, there was no statistical significance because of the reduced number of parameters available. In the presence of infection, fractures, and pregnancy/ childbirth, there was a correlation between lymphocyte

Table 3 Frequency of albumin and lymphocytes cases within normal range of laboratory

\begin{tabular}{|c|c|c|c|c|c|c|}
\hline \multirow[t]{2}{*}{ Ward } & \multirow[b]{2}{*}{ Total patients } & \multicolumn{2}{|l|}{ Albumin } & \multirow[b]{2}{*}{ Total patients } & \multicolumn{2}{|l|}{ Lymphocytes } \\
\hline & & $\begin{array}{l}\text { Within normal } \\
\text { range }\end{array}$ & $\begin{array}{l}\% \text { Normal } \\
\text { range }\end{array}$ & & $\begin{array}{l}\text { Within normal } \\
\text { range }\end{array}$ & $\begin{array}{l}\% \text { Normal } \\
\text { range }\end{array}$ \\
\hline Surgery $1^{\text {st }}$ & 101 & 53 & $52 \%$ & 411 & 314 & $76 \%$ \\
\hline Surgery $2^{\text {nd }}$ & 160 & 78 & $49 \%$ & 343 & 230 & $67 \%$ \\
\hline Gynecology & 7 & 0 & $0 \%$ & 149 & 128 & $86 \%$ \\
\hline Obstetrics & 35 & 23 & $66 \%$ & 1184 & 1065 & $90 \%$ \\
\hline Infectious diseases & 150 & 52 & $35 \%$ & 206 & 127 & $62 \%$ \\
\hline Medicine $1^{\text {st }}$ & 432 & 125 & $29 \%$ & 550 & 336 & $61 \%$ \\
\hline Medicine 2nd & 237 & 60 & $25 \%$ & 345 & 214 & $62 \%$ \\
\hline Medicine 3rd & 206 & 47 & $23 \%$ & 291 & 183 & $63 \%$ \\
\hline Orthopedics & 71 & 56 & $79 \%$ & 278 & 221 & $79 \%$ \\
\hline Urology & 38 & 11 & $29 \%$ & 281 & 204 & $73 \%$ \\
\hline Total & 1437 & 505 & $35 \%$ & 4038 & 3022 & $75 \%$ \\
\hline
\end{tabular}


Table 4 Correlations between albumin, lymphocytes, co-morbidities, and length of hospital stay

\begin{tabular}{lllll}
\hline & $\begin{array}{l}\text { Hospital } \\
\text { days }\end{array}$ & Albumin & Lymphocytes & $\begin{array}{l}\mathrm{N}^{\circ} \\
\text { Comorbidities }\end{array}$ \\
\hline Hospital days & 1 & -0.22251 & -0.06075 & 0.31493 \\
Albumin & -0.22251 & 1 & 0.07475 & -0.21698 \\
& $<.0001$ & & 0.0049 & $<.0001$ \\
Lymphocytes & -0.06075 & 0.07475 & 1 & -0.01401 \\
& 0.0221 & 0.0049 & & 0.00221 \\
No Comorbidities & 0.31493 & -0.21698 & -0.01401 & 1 \\
& $<.0001$ & $<.0001$ & 0.5981 & \\
\hline Number of patients $=1428$ & & &
\end{tabular}

count and length of stay, with no other relationship for other diagnoses between lymphocyte count and length of stay.

\section{Multivariate Analysis and Regression}

From the preliminary descriptive study, we observed that the classic model of linear regression was inadequate for our study due to the distribution of the variable "hospital days" (Figs. 3 and 4). In fact, the classical model requires the assumption that the distribution of the errors (as well as the variables considered) is Normal, condition that does not occur in our case. Therefore we adopted the method 'stepwise backward' to better fit our model and our needs to study the effects of each variable involved. In Table 7 we show the parameters studied, according to the method of maximum likelihood. The hypothesis tested in this case is the significance of the variable Albumin and length of hospital stay. Because of the large number of variables involved, multivariate statistical method was required. Factorial analysis through Principal Component method, with a limited loss of information, has eliminated the multi-collinearity between the original variables. Reducing the number of factors considered, regression has shown that platelets, advanced age, number of co-morbidities, diagnosis, gender and type of admission are all significant variables in explaining LOS. In particular, for every unit increase in the number of platelets there was a small increase in length of stay, and the value found for the type of admission indicates that LOS decreased by approximately $19 \%$ if recovery changed from "urgent" to "elective".

For the variable "Diagnosis" the probability of incurring in a longer length of stay is higher in case of fractures; the risk increases by $24 \%$ passing from the diagnosis of malignant tumor to fracture, but in the case of inflammatory diseases the coefficient appears not significant. We can conclude that all variables shown in Table 8 are highly significant in explaining patients' length of stay. Finally, also patients gender helps to explain the phenomenon analyzed; under this aspect, women had a lower risk of incurring in a long hospital stay, as it is not taken into account in the regression model.

About the Discriminant function analysis, which compared patients with and without albumin, we found that only 7 of the 16 variables initially selected as discriminant inputs are effectively correlated with the measurement of the albumin parameter (Table 9). Therefore, we can state that in the group with albumin value, patients have higer age at admission, increased hospital stay (number of days), a higher concentration of platelets (more than $45010^{\wedge} 3 / \mathrm{uL}$ ) and eosinophils (higer than 0.5 $10^{\wedge} 3 / \mathrm{ul}$ ), but lower level of White Blood Cells (less than $4.0 \times 10^{\wedge} 3 / \mathrm{ul}$ ) and MCHC (lower than $31.5 \mathrm{~g} / \mathrm{dl}$ ). Furthermore, we can't say with sufficient certainty whether the type of surgery have significantly influenced patients' length of stay. In the sample studied, the surgical procedures performed were 534 and highly heterogeneous (251 different types of surgical interventions). This

Table 5 Correlation between albumin and lymphocytes and length of hospital stay, by ward

\begin{tabular}{|c|c|c|c|c|c|c|}
\hline \multirow[t]{2}{*}{ Ward } & \multirow[b]{2}{*}{ Patients } & \multicolumn{2}{|l|}{ Albumin } & \multirow[b]{2}{*}{ Patients } & \multicolumn{2}{|c|}{ Lymphocytes } \\
\hline & & r & $p$ & & r & $p$ \\
\hline Surgery $1^{\text {st }}$ & 101 & -0.40901 & $<0.0001$ & 378 & -0.13963 & 0.0065 \\
\hline Surgery $2^{\text {nd }}$ & 160 & -0.21696 & 0.0059 & 326 & -0.03280 & 0.5551 \\
\hline Gynecology & 7 & 0.08426 & 0.8575 & 111 & -0.11816 & 0.2168 \\
\hline Obstetrics & 35 & -0.02260 & 0.8975 & 743 & -0.03041 & 0.4078 \\
\hline Infectious diseases & 150 & -0.30501 & 0.0001 & 203 & -0.13200 & 0.0605 \\
\hline Medicine $1^{\text {st }}$ & 432 & -0.23764 & $<0.0001$ & 543 & -0.07096 & 0.0986 \\
\hline Medicine ${ }_{2}$ nd & 237 & -0.22700 & 0.0004 & 341 & -0.09080 & 0.0941 \\
\hline Medicine ${ }_{3} r d$ & 206 & -0.17835 & 0.0103 & 285 & -0.09362 & 0.1148 \\
\hline Orthopedics & 71 & -0.24059 & 0.0433 & 229 & -0.17315 & 0.0086 \\
\hline Urology & 38 & -0.39124 & 0.0151 & 216 & -0.04059 & 0.5530 \\
\hline
\end{tabular}

Small samples are indicated in red bold 
Table 6 Correlation between albumin and lymphocytes and length of hospital stay, by diagnosis

\begin{tabular}{|c|c|c|c|c|c|c|}
\hline \multirow[t]{2}{*}{ Diagnosis } & \multirow[b]{2}{*}{ Patients } & \multicolumn{2}{|l|}{ Albumin } & \multirow[b]{2}{*}{ Patients } & \multicolumn{2}{|c|}{ Lymphocytes } \\
\hline & & r & $p$ & & r & $p$ \\
\hline Malignant tumors & 206 & -0.16027 & 0.0214 & 343 & -0.00565 & 0.9170 \\
\hline Benign tumors & 11 & -0.22459 & 0.5067 & 85 & -0.15118 & 0.1672 \\
\hline Inflammatory diseases & 95 & -0.17584 & 0.0883 & 206 & -0.12299 & 0.0782 \\
\hline Infections & 397 & -0.23001 & $<0.0001$ & 649 & -0.12547 & 0.0014 \\
\hline Hemorrhagic conditions & 60 & -0.35899 & 0.0049 & 131 & -0.05823 & 0.5089 \\
\hline Fractures & 71 & -0.31096 & 0.0083 & 202 & -0.14823 & 0.0353 \\
\hline Pregnancy/Childbirth & 26 & -0.52093 & 0.0064 & 613 & -0.08906 & 0.0275 \\
\hline Others & 567 & -0.23845 & $<0.0001$ & 1146 & -0.04780 & 0.1058 \\
\hline
\end{tabular}

Small samples are indicated in red bold

obstacle made it difficult to group or analyze the procedures in relation to LOS, so we are not able to draw any conclusions of scientific or statistical value.

\section{Discussion}

\section{Summary: aims and main results}

The correlation between reduced albumin levels and prolonged hospitalization applied to the entire sample and to almost all hospital wards (except for gynecology and obstetrics), and also to certain diseases like benign tumors and inflammatory diseases. Even though a low blood lymphocyte count was associated with longer LOS in the entire sample, the results were only significant in the ward of orthopedics and surgery. Only for the diagnosis of certain clinical conditions like infectious diseases, fractures and pregnancy/childbirth, a low blood lymphocyte count correlated with prolonged hospital stay. Using the regression method platelets, advanced age, number of co-morbidities, diagnosis, gender and type of admission were significant variables associated with prolonged hospital stay, yielding important information that could be used to improve current nutritional screening tools.

\section{Possible mechanisms and explanations for the findings}

Our results indicate that low albumin levels have a close correlation with longer hospital stays, while the relationship with lymphocyte count is only marginal, in accordance with previous studies [17]. Low lymphocyte counts lead to prolonged hospitalization mainly in the presence of infectious diseases, probably because lymphocytes play a critical role in the immune response against the pathogens involved. In the orthopedics ward, a decreased lymphocyte count leads to a significant increase in hospital days, mainly due to trauma and/or inflamation $[7,18,19]$. ACTH, corticosteroids, catecholamines, cytokines, chemokines and allarmines play an important role in the initiation and maintenance of the inflammatory response to injury, and also in the regulation of the albumin gene expression [8]. The complex

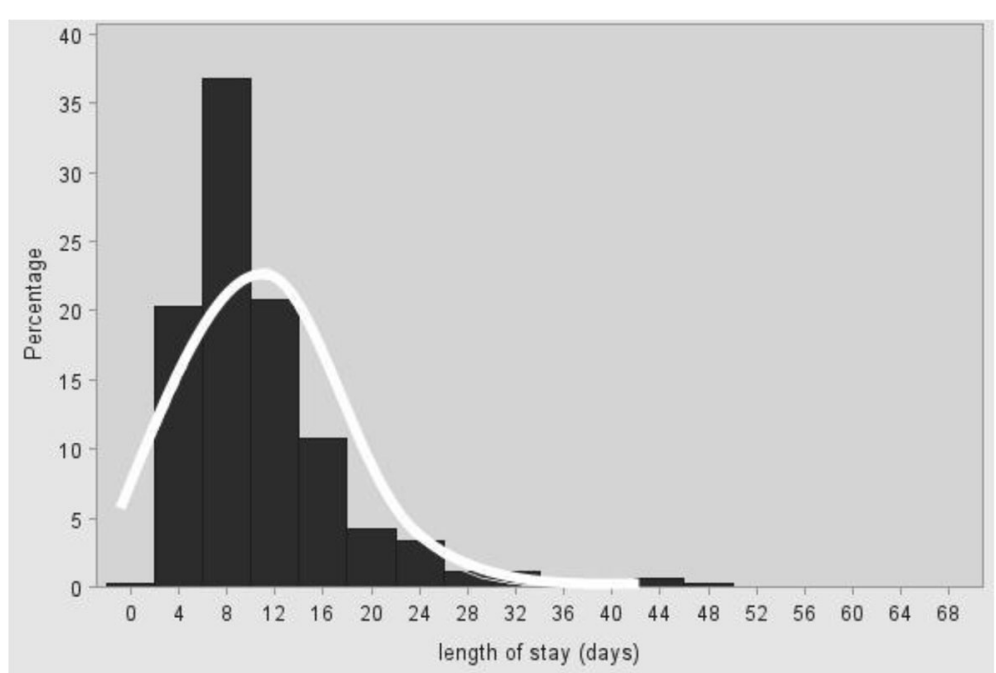

Fig. 3 Percentage of patients with a given length of stay (in days). Legend. The line describes the fitted Normal distribution 


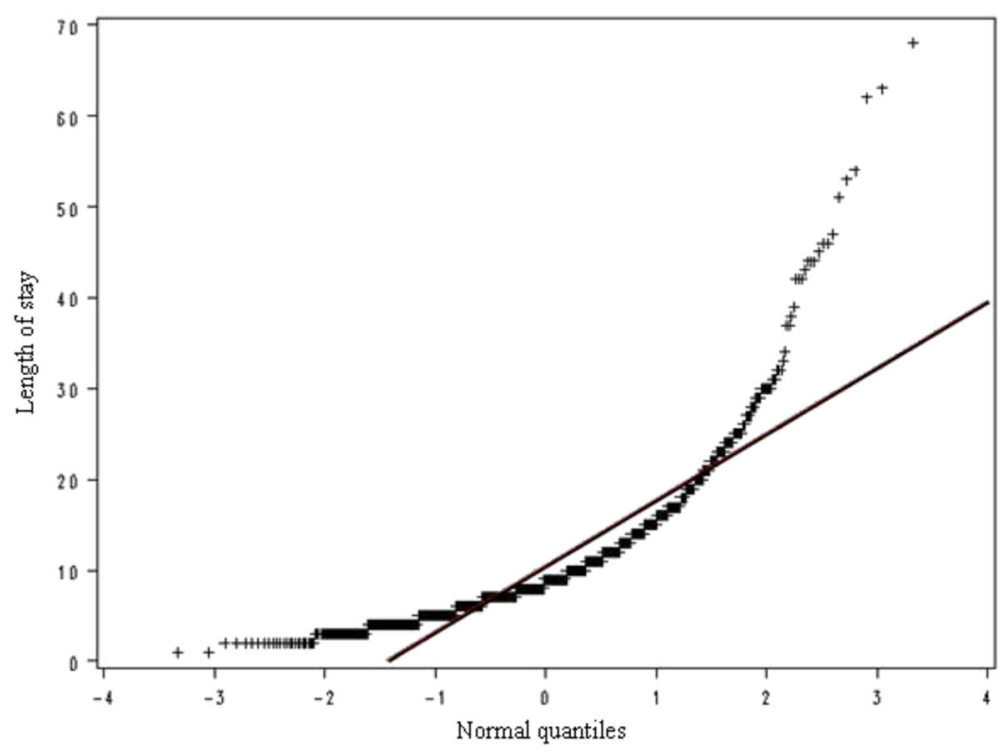

Fig. 4 Normal Quantile-Quantile Plot for length of stay. Legend. The plot compares the ordered values of length of stay (days) with quantiles of the normal distribution. If the data distribution matches the theoretical distribution, the points on the plot form a linear pattern

network of cytokines appears to be disrupted, especially after surgery [20]. Interleukin-1 $\beta,-6,-8$ and TNF- $\alpha$, some suppressive cytokines such as Interleukin-10, -4 and Interleukin-1 receptor antagonist significantly increase just after the beginning of surgery, while Interferon- $\gamma$ and Interleukin-2 are markedly reduced [20]. This imbalance alters the immune response and may in part explain the correlation between low levels of lymphocytes and length of stay found in surgery ward I.

\section{Strengths and limitations of the study}

The main strengths of this study consist in the large amount of data at our disposal, and in the homogeneity of the sample, obtained through the standardization linked to the use of patient electronic charts; this allowed to identify various pathologies and comorbidities through the use of international codes. The results obtained confirm the hypothesis that low albumin levels and low lymphocyte counts are associated with increased length of stay; the relationship applied to the entire sample examined, and the strength of correlation was higher in some wards, and might be applied to any kind of hospital.

This study has also highlighted some critical points of the clinical approach: limited evaluation of albumin at admission, and inability to trace the anthropometric data

Table 7 Regression analysis - estimates of maximum likelihood

\begin{tabular}{|c|c|c|c|c|c|c|c|}
\hline Parameter & Level_1 & Estimate & Standard Error & Lim. Conf. $<95 \%$ & Lim. Conf. > 95\% & $x^{2}$ Wald & $\operatorname{Pr}>x^{2}$ \\
\hline Albumin & & -0.1479 & 0.0473 & -0.2405 & -0.0553 & 9.79 & 0.0018 \\
\hline Lymphocytes & & 0.0717 & 0.0415 & -0.0097 & 0.1530 & 2.98 & 0.0843 \\
\hline Number of Comorbidities & & 0.2625 & 0.0255 & 0.2125 & 0.3126 & 105.76 & $<0.0001$ \\
\hline Red Blood Cells & & 0.1008 & 0.0428 & 0.0170 & 0.1846 & 5.56 & 0.0184 \\
\hline Platelets & & 0.0008 & 0.0003 & 0.0001 & 0.0014 & 5.88 & 0.0154 \\
\hline Diagnosis 1 & Infections & -0.0334 & 0.1631 & -0.3531 & 0.2863 & 0.04 & 0.8376 \\
\hline Diagnosis 2 & Malignant tumors & 0.0600 & 0.1208 & -0.1768 & 0.2967 & 0.25 & 0.6195 \\
\hline Diagnosis 3 & Benign tumors & 0.4561 & 0.2490 & -0.0320 & 0.9441 & 3.35 & 0.0670 \\
\hline Diagnosis 4 & Other & -0.0107 & 0.1310 & -0.2675 & 0.2461 & 0.01 & 0.9347 \\
\hline Diagnosis 5 & Fracture & 0.2357 & 0.1305 & -0.0200 & 0.4913 & 3.26 & 0.0708 \\
\hline Diagnosis 6 & Pregnancy and childbirth & -0.5629 & 0.2357 & -1.0249 & -0.1009 & 5.70 & 0.0169 \\
\hline Diagnosis 7 & Haemorrhagic conditions & -0.0037 & 0.1764 & -0.3494 & 0.3420 & 0.00 & 0.9834 \\
\hline Diagnosis 8 & Inflammatory diseases & 0 & 0 & 0 & 0 & . & . \\
\hline
\end{tabular}


Table 8 Likelihood ratio - significance analysis

\begin{tabular}{lllll}
\hline Origin & $x^{2}$ & $\operatorname{Pr}>x^{2}$ & Index & Hospital days \\
\hline Platelets & 29.14 & $<0.0001$ & $\uparrow$ & $\uparrow$ \\
Age & 52.23 & $<0.0001$ & $\uparrow$ & $\uparrow$ \\
Number of Co-morbidities & 289.12 & $<0.0001$ & $\uparrow$ & $\uparrow$ \\
Diagnosis & 125.36 & $<0.0001$ & Inflammatory diseases \\
& & & excluded \\
Gender & 8.33 & 0.0039 & Male & $\uparrow$ \\
Recovery & 21.15 & $<0.0001$ & Urgent & $\uparrow$ \\
\hline
\end{tabular}

of patients. Anthropometric data and albumin levels were regularly measured before surgical procedures, in order to properly administer general anesthesia, antibiotics, or chemotherapeutic drugs, but not to determine the patient general health status. Clinicians carelessness about nutritional status has led to a general disinterest for important parameters such as weight, height, BMI and selected biochemical markers [21, 22]. Albumin measurement is an important low-cost instrumental exam, still marginally used in hospitals. Also anthropometric data are important for the assessment of nutritional status, but they are rarely measured, even though recent studies confirmed that these parameters represent the most predictive factor in determining the risk of complications: for instance, BMI values below $20 \mathrm{~kg} / \mathrm{m}^{2}$ determine hospital stays 2.1 times longer compared to hospitalization for BMI within normal range; albumin and lymphocytes severely affect the length of hospitalization [23-26].

\section{The importance of an early assessment of albumin and lymphocytes}

The present study has highlighted the importance of an early assessment of albumin levsls. Low levels of albumin can be caused by various factors, like decreased food and calorie intake due to hospitalization [27], prolonged fasting [27], surgical operations [19], postural changes [13], cytokines [13], drugs [28], hormonal therapies [19], inflammatory diseases, liver and kidney diseases, cancer, infections and all medical conditions characterized by high metabolic energy requirement. Sepsis, for instance, can influence synthesis, consumption, and distribution of albumin between intra and extravascular compartments [11, 12, 18]. Rapid changes in albumin levels are common after admission, and the "sink rate" is very rapid especially after admission. Researchers have suggested that the sink rate is too fast to be associated only with patients nutritional deterioration [26]. Posture modification, from standing to reclined position, was shown to cause a decrease in serum albumin: the production of TNF- $\alpha$, Interleukin- 2 and -6 , inhibits the synthesis of albumin by acting on its gene expression, through a down-regulation process [13]. Since lymphocytes are involved in the immune response, decreased lymphocyte counts are considered an indicator of the general decline of physiological functions, and factors of poor prognosis in hospitalized patients [11].

\section{Clinical implications and future perspectives}

With this research we intended to raise clinicians attention to the importance of albumin and lymphocytes to assess the status of hospitalized patients. It would have been useful and important to evaluate also patient anthropometric parameters which would have given the study a more complete analysis. These health indices, once routinely recorded by nursing staff, are now considered as the major reason of wasting time dedicated to more invasive clinical procedures. Therefore in light of the fact of there being no screening method universally accepted, we aim to provide guidelines for the assessment of patients health status in different contexts (community, hospitals, patients with specific diseases, etc). Low albumin levels and low lymphocytes count are

Table 9 Stepwise selection for patients with albumin value

\begin{tabular}{|c|c|c|c|c|c|c|c|c|}
\hline \multicolumn{9}{|c|}{ Summary of stepwise selection } \\
\hline \multicolumn{2}{|c|}{ Step Input } & \multirow{2}{*}{$\begin{array}{l}\mathrm{R}^{2} \text { (partial) } \\
0,1664\end{array}$} & \multirow{2}{*}{$\begin{array}{l}\text { F Value } \\
658,77\end{array}$} & \multirow{2}{*}{$\begin{array}{l}\operatorname{Pr}>F \\
<, 0001\end{array}$} & \multirow{2}{*}{$\begin{array}{l}\text { Lambda Wilks } \\
0,8336\end{array}$} & \multirow{2}{*}{$\begin{array}{l}\operatorname{Pr}<\text { Lambda } \\
<, 0001\end{array}$} & \multirow{2}{*}{$\begin{array}{l}\text { Average Squared } \\
\text { Canonical Correlation } \\
0,1664\end{array}$} & \multirow{2}{*}{$\begin{array}{l}\mathrm{Pr}>\mathrm{ASCl} \\
<, 0001\end{array}$} \\
\hline 1 & Age at recovery & & & & & & & \\
\hline 2 & Days of recovery & 0,0454 & 156,69 & $<, 0001$ & 0,7957 & $<, 0001$ & 0,2043 & $<, 0001$ \\
\hline 3 & $\begin{array}{l}\text { White blood count (WBC) } \\
10 \wedge 3 / \mathrm{ul} 4.0-10.0\end{array}$ & 0,0049 & 16,31 & $<, 0001$ & 0,7918 & $<, 0001$ & 0,2082 & $<, 0001$ \\
\hline 4 & $\begin{array}{l}\text { Monocytes (absolute nr) } \\
\text { 10^3/ul } 0.2-1.0\end{array}$ & 0,0024 & 8,03 & 0,005 & 0,7899 & $<, 0001$ & 0,2101 & $<, 0001$ \\
\hline 5 & $\begin{array}{l}\text { Mean corpuscular hemoglobin } \\
\text { concentration (MCHC) g/dl } 31.5-34.5\end{array}$ & 0,0021 & 6,84 & 0,009 & 0,7883 & $<, 0001$ & 0,2117 & $<, 0001$ \\
\hline 6 & Platelets (PLT) 10^3/uL $150-450$ & 0,0017 & 5,58 & 0,018 & 0,7869 & $<, 0001$ & 0,2131 & $<, 0001$ \\
\hline 7 & Eosinophils (absolute nr) 10^3/ul $0.0-0.5$ & 0,0012 & 3,81 & 0,051 & 0,7860 & $<, 0001$ & 0,2140 & $<, 0001$ \\
\hline
\end{tabular}


directly related to longer hospital stays, and therefore the alteration of these markers causes a further deterioration of the nutritional status, thus promoting a cycle of malnutrition-infection leading to the onset of proteinenergy malnutrition, a self-perpetuating process with a strong influence on patient outcomes (poor wound healing, loss of muscle strength, decreased mobility, increased risk of thromboembolic complications [27, 28]), length of stay and associated costs [29, 30].

Our challenge for the future is to convince clinicians on the importance of assessing albumin and lymphocytes and eventually doing a whole nutritional assessment of the single patient.

\section{Conclusion}

We can conclude portraying the data of a study conducted in 2003 in which it has been described that with a reduction of $1 \mathrm{~g} / \mathrm{dl}$ in serum albumin, hospital days had increased by $71 \%$ [31]. This finding grabbed our attention; in our study 924 patients had an albumin concentration below the lower limit $(3.5 \mathrm{~g} / \mathrm{dl})$ of which 750 with a reduction of $1 \mathrm{~g} / \mathrm{dl}, 169$ with a decrease of $2 \mathrm{~g} / \mathrm{dl}$ and 5 with less than $3 \mathrm{~g} / \mathrm{dl}$. Considering that for each gram lost of albumin there is a theoretical probability $71 \%$ increase in longer hospitalization and that albumin in our sample was evaluated in only $36 \%$ of our cases, and assuming that the distribution of the decline of albumin may be similar even in the population which albumin has not been evaluated, there are three questions to be asked: how many days patients have unnecessarily spent in hospital? How much have these additional days of hospitalization weighed, from an economic point of view, in the absence of albumin assessment? And more important, how much the extra days of hospitalization would have not economically impacted the hospital with an appropriate nutritional assessment? Exploiting new clinical knowledge and investing time to ensure maximum therapeutic benefit for each patient means to act in the interest of the community. One should invest time and resources during the first steps of admission, in order to assess patients real health status, and to create a personalized plan for recovery. This important concept is the rationale that guided us to conduct this research, but it should also be the reason that accompanies any decision of each health care professional in his profession.

\section{Abbreviations}

BIA: Body impedance assessment; GLM: Generalized linear models; LOS: Length of stay

\section{Aknowledgments}

We thank Dr. Gerardo Cioffi, native speakers, for reviewing the English language
Funding

No source of funding has a role in the study's design, conduct, and reporting.

Availability of data and materials

"Availability of data and materials" supporting their findings can be found.

Authors' contributions

All those designated as authors meet all four criteria for authorship having covered a specific role in writing the manuscript, as stated in the ICMJE Recommendations. AEP designed research; MR, LL, FR and AB conducted research and wrote the paper; LF reviewed the manuscript; EDP analyzed data and reviewed statistical section; each Author had a specific responsibility for final content, LF, MDS and UC reviewed the manuscript, analyzed data and reviewed statistical section; each Author had a specific responsibility for final content. All Authors read and approved the final manuscript.

\section{Competing interests}

We confirm that there are no known conflicts of interest associated with this work and there has been no significant financial support that could have influenced its outcome.

\section{Consent for publication}

Written informed consent was obtained from the patients of this study for the publication of personal data and images

\section{Ethics approval and consent to participate}

This retrospective study took place in Hospital San Paolo of Milan after the study protocol was approved by the local Ethics Committee.

Written informed consent to participate was obtained from the patients included in the study.

\section{Data sharing}

We provide as attachments the database containing all the information collected to perform the study and all documents related to it (Ethics Committee approval, informed consent, consent for the processing of personal data, study protocol and synopses).

\section{Publisher's Note}

Springer Nature remains neutral with regard to jurisdictional claims in published maps and institutional affiliations.

\section{Author details \\ ${ }^{1}$ 2nd Division of Medicine, Ospedale San Paolo and University of Milan, Milan, Italy. ${ }^{2}$ 2nd Division of Surgery, Ospedale San Paolo and University of Milan, Milan, Italy. ${ }^{3}$ Division of Thoracic Surgery, Ospedale San Paolo and University of Milan, Milan, Italy. ${ }^{4}$ Department of Surgery, University of Milan, Milan, Italy.}

Received: 13 December 2016 Accepted: 6 March 2017 Published online: 21 March 2017

\section{References}

1. Waitzberg DL, Caiaffa WT, Correia MI. Hospital malnutrition: the Brazilian national survey (IBRANUTRI): a study of 4000 patients. Nutrition. 2001;17(7-8):573-80.

2. Lee H, Cho YS, Jung S, Kim H. Effect of nutritional risk at admission on the length of hospital stay and mortality in gastrointestinal cancer patients. Clin Nutr Res. 2013;2(1):12-8.

3. Farrugia A. Albumin usage in clinical medicine: tradition or therapeutic? Transfus Med Rev. 2010;24(1):53-63.

4. Kuzuya M, Kanda S, Koike T, Suzuki Y, Iguchi A. Lack of correlation between total lymphocyte count and nutritional status in the elderly. Clin Nutr. 2005;24(3):427-32

5. Lomivorotov W, Efremov SM, Boboshko VA, Leyderman IN, Lomivorotov VN, Cheung AT, et al. Preoperative total lymphocyte count in peripheral blood as a predictor of poor outcome in adult cardiac surgery. J Cardiothorac Vasc Anesth. 2011;25(6):975-80

6. Rubio-Rivas M, Formiga F, Grillo S, Gili F, Cabrera C, Corbella X. Lymphopenia as prognostic factor for mortality and hospital length of stay for elderly hospitalized patients. Aging Clin Exp Res. 2016;28(4):721-7. 
7. Roubenoff R, Roubenoff RA, Preto J, Balke W. Malnutrition among hospitalized patients. A problem of physician awareness. Arch Intern Med. 1987;147(8):1462-5.

8. Bistrian BR, Blackburn GL, Vitale J, Cochran D, Naylor J. Prevalence of malnutrition in general medicine patients. JAMA. 1976;235(15):1567-70.

9. Volkert D, Kruse W, Oster P. Malnutrition in geriatric patients: diagnostic and prognostic significance of nutritional parameters. Ann Nutr Metab. 1992; 36(2):97-112.

10. Doweiko JP, Nompleggi DJ. Role of albumin in human physiology and pathophysiology. JPEN. 1991;15(2):207-11.

11. Bellantone R, Doglietto GB, Bossola M, Pacelli F, Negro F, Crucitti F. Validity of serum albumin, total lymphocyte count, and weight loss in predicting postoperative nutrition-associated complications. Nutrition. 1990;6(3):264-6.

12. Nicholson JP, Wolmarans MR, Park GR. The role of albumin in critical illness. Br J Anaesth. 2000;85(4):599-610.

13. Omran ML, Morley JE. Assessment of protein energy malnutrition in older persons, part l: history, examination, body composition, and screening tools. Nutrition. 2000;16(1):50-63.

14. De Luis DA, Terroba MC, Cuellar L, Izaola O, de la Fuente B, Martin T, et al. Association of anthropometric and biochemical markers with length of stay and mortality in the hospital. Eur Rev Med Pharmacol Sci. 2013;17(10):1321-5.

15. Shepperd S, Doll H, Angus RM, Clarke MJ, lliffe S, Kalra L, et al. Avoiding hospital admission through provision of hospital care at home: a systematic review and meta-analysis of individual patient data. CMAJ. 2009;180(2):175-82.

16. Tucker HN, Miguel SG. Cost containment through nutrition intervention. Nutr Rev. 1996;54(4 Pt 1):111-21.

17. Pardo Cabello AJ, Bermudo Conde S, Manzano Gamero MV. Prevalence and factors associated to malnutrition in patients admitted to a medium-long stay hospital. Nutr Hosp. 2011;26(2):369-75.

18. Hildebrand F, Pape HC, Krettek C. The importance of cytokines in the posttraumatic inflammatory reaction. Unfallchirurg. 2005:108(10):793-4. 796-803.

19. Lenz A, Franklin GA, Cheadle WG. Systemic inflammation after trauma. Injury. 2007;38(12):1336-45.

20. Cioca DP, Watanabe N, Isobe M. Apoptosis of peripheral blood lymphocytes is induced by catecholamines. Jpn Heart J. 2000;41(3):385-98.

21. McWhirter JP, Pennington CR. Incidence and recognition of malnutrition in hospital. BMJ. 1994;308(6934):945-8.

22. De Luis DA, Izaola O, Cuellar L, Terroba MC, Cabezas G, Rojo S, et al. Nutritional assessment: predictive variables at hospital admission related with length of stay. Ann Nutr Metab. 2006;50(4):394-8.

23. Gianotti L, Braga M, Radaelli G, Mariani L, Vignali A, Di Carlo V. Lack of improvement of prognostic performance of weight loss when combined with other parameters. Nutrition. 1995;11(1):12-6.

24. Valente da Silva HG, Santos SO, Silva NO, Ribeiro FD, Josua LL, Moreira AS Nutritional assessment associated with length of inpatients' hospital stay. Nutr Hosp. 2012;27(2):542-7.

25. Gupta D, Vashi PG, Lammersfeld CA, Braun DP. Role of nutritional status in predicting the length of stay in cancer: a systematic review of the epidemiological literature. Ann Nutr Metab. 2011;59(2-4):96-106.

26. Gärtner S, Kraft M, Krüger J, Vogt LJ, Fiene M, Mayerle J, et al. Geriatric nutritional risk index correlates with length of hospital stay and inflammatory markers in older inpatients. Clin Nutr. 2016.

27. Seiler WO. Clinical pictures of malnutrition in ill elderly subjects. Nutrition. 2001;17(6):496-8.

28. Johnson AM. Low levels of plasma proteins: malnutrition or inflammation? Clin Chem Lab Med. 1999;37(2):91-6.

29. Keusch GT. The history of nutrition: malnutrition, infection and immunity. J Nutr. 2003;133(1):336S-40S.

30. Lang CH, Frost RA, Vary TC. Regulation of muscle protein synthesis during sepsis and inflammation. Am J Physiol Endocrinol Metab. 2007:293:E453-9.

31. Vincent JL, Dubois MJ, Navickis RJ, Wilkes MM. Hypoalbuminemia in acute illness: is there a rationale for intervention? A meta-analysis of cohort studies and controlled trials. Ann Surg. 2003;237(3):319-34.

\section{Submit your next manuscript to BioMed Central and we will help you at every step:}

- We accept pre-submission inquiries

- Our selector tool helps you to find the most relevant journal

- We provide round the clock customer support

- Convenient online submission

- Thorough peer review

- Inclusion in PubMed and all major indexing services

- Maximum visibility for your research

Submit your manuscript at www.biomedcentral.com/submit
Biomed Central 